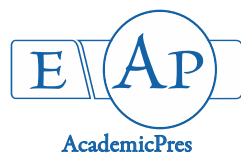

\title{
Effectiveness of Various Solar Light Traps With and Without Sex Pheromone for Mass Trapping of Tomato Leaf Miner (Tuta absoluta) in a Tomato Field
}

\author{
Hossein PEZHMAN*, Karim SAEIDI \\ Fars Agricultural and Natural Resources Research and Education Center, Department of Plant Protection Research, AREEO, Shiraz, Iran; \\ hossein.pezhman@yahoo.com ("correspondingauthor); saeidi391@yahoo.com
}

\begin{abstract}
Tuta absolute was a quarantine pest in Iran that has been recorded for the first time in 2009. The most conventional methods for control of this pest in Iran are chemical methods and mass trapping, although the efficiency of the latter method is not clear. In 2013, the efficiency of three common types of solar light traps with and without sex pheromone, along with water pan pheromone traps for control, were investigated. The experiment was performed in a randomized complete block design within in a tomato field. The treatments were Behroyan light trap (BL), Zist bani light trap (ZL), Russell light trap (RL), BL + pheromone, $\mathrm{ZL}+$ pheromone, RL+ pheromone and water pan pheromone trap (WPT). Traps were checked weekly and the number of captured tomato leaf miner (TLM), Noctuid moths, Chrysopa sp., Coccinella septempuctata and Syrphid flies were counted. Mean weekly capture of TLM in BL, ZL and RL traps without sex pheromone were $9.11 \pm 1.16,4.94 \pm 0.24$ and $1.66 \pm 0.7$, while within traps sex pheromone were $54.72 \pm 11.8,42.05 \pm 6.47,39.02 \pm 2.82$, respectively. The mean weekly capture of Noctuid moths in the traps without pheromone were $16.92 \pm 1.39,25.39 \pm 0.57,1.49 \pm 0.27$ and with pheromone were $21.04 \pm 1.72,28.09 \pm 0.95,2.76 \pm 1.39$, respectively. Mean weekly capture of TLM and Noctuid moths in WPT traps were $47.13 \pm 3.06$ and $0.73 \pm 0.27$, respectively. The total attracted numbers of predators by the three light traps were not significant. In conclusion, traps baited sex pheromone (especially BL and ZL) could be used as eco- friendly tools for mass trapping of TLM and some key Noctuid moth pests in isolated tomato fields.
\end{abstract}

Keywords: light traps; noctuid moths; predators; quarantine pest; water pan traps

\section{Introduction}

Tomato, Solanum lycopersicum L., is one of the most popular vegetable crops in Iran .It is widely grown both in open fields and greenhouses. Tomato fruit is rich in nutrients such as vitamins, minerals and antioxidants. According to Ministry of Agriculture report of 2013 2014, 6.24 million tons of tomato have been harvested from 158.2 thousands hectares of cultivated areas in Iran so that, Fars province with 14.5 percent of the total tomato production was placed in the first position (Anonymous, 2014).

Tomato is attacked by a wide range of arthropod pests. The most common pests on tomato in Iran are tomato fruit borer (Helicoverpa armigera Hubner), tomato army worms (Spodoptera spp.), cut worms (Agrotis spp.), white fly (Bemisia tabaci Gennodius), aphids (Aphis spp.), leaf miner (Liriomyza trifolii Burgess), two spotted spider mite
(Tetranychus urticae Koch) (Khanjani, 2013) and tomato leaf miner moth (Tuta absoluta Meyrick) (Baniameri and Cheraghani, 2012).

Tuta abosluta (Lepidoptera: Gelechiidae) was first described in Peru in 1917 (Meyrick, 1917) and then spread rapidly in all of the tomato-producing areas (Urbaneja et al., 2007; Viggiani et al., 2009; Abdul Razzak et al., 2010; Desneux et al., 2010; Kilic, 2010). It was first recorded in 2010 from Urmia city, North West of Iran (Baniameri and Cheraghani, 2012), then rapidly spread in the majority of tomato producing areas and became one of the most important pests of tomato. T. absoluta is a major pest of processing and fresh tomatoes, both in greenhouse and open fields (Desneux et al., 2010). The damages of larvae feeding is through mining leaves, stems and buds, burrowing tunnels in the fruits that result in low marketability of fresh tomatoes and yield losses up to $90-100 \%$ (Vargas, 1970). The preferred host of this pest is tomato (Solanum 
476

lycopersicum L.), but it has also been recorded on potato (Solanum tuberosum L.), eggplant (Solanum melongena L.), tobacco (Nicotiana tabacum L.), bean (Phaseoulus vulgaris L.), pepino (Solanum muricatum Aiton), Cape gooseberry (Physalis peruviana L.) (Desneux et al., 2010) and some wild plants such as Solanum nigrum L., Datura stramonium L., Lycium chinense Mill. and Malva sp. (Pereyra and Sanchez, 2006; Desneux et al., 2010).

The control of $T$. absoluta is very challenging (Korycinska et al., 2009); chemical control is a common method to manage this pest (Galarza et al., 1984), but it has low efficiency (Cocco et al., 2013). Therefore, alternative and more environmental friendly control methods such as biological control (Torres et al., 2002; Gonzalez-Cabrera et al., 2011), mating disruption with sex pheromones (Carde 2007; Vacas et al., 2011; Cocco et al., 2012) and mass trapping by light traps (Oliveira et al., 2008; Emre and Orkun, 2016) and pheromone water pan traps (Emre and Orkun, 2016) have been proposed to control T. absoluta. The female sex pheromone of $T$. absoluta was identified in the late 1990s and pheromone blends were subsequently tested, aiming their use for field monitoring and mass trapping (Ferrara et al., 2001). The female sex pheromone is highly effective in attraction of male population of tomato leaf miners (Filho et al., 2000). For mass trapping, a high density of pheromone baited traps in strategic positions within a crop can be effective (Jones, 1998). Capturing a large numbers of male adults result in an imbalance in the pest sex ratio, this impacts the mating pattern of the pest (USDA APHIS, 2011). Hence, sex pheromone-based strategies are promising techniques to control this invasive pest (Hassan and Al-Zaidi, 2010).

In the present survey upon the management of $T$. absoluta mass trapping using various types of light traps with and without sex pheromone as a new control method in Iran was used. The main goals of the study were: (1) evaluating the efficiency of the three most conventional available solar light traps in Iran, with and without sex pheromone for mass trapping of T. absoluta in an open tomato field in Fars province; (2) determining the attractiveness of above mentioned traps for the important predators in tomato fields; and (3) determining the performance of the experimental traps for mass trapping of some important noctuid moths pests in tomato fields in order to production of organic yield.

\section{Materials and Methods}

Site of study

The study was carried out in spring and summer seasons (2013) in a tomato field of Baiza district (1995 m above sea level, $52^{\circ} 43$ 'E and $29^{\circ} 96^{\prime} \mathrm{N}$ ), locating at $35 \mathrm{~km}$ of Shiraz Northwest in Fars province (Iran). The experimental field was about 1.2 ha and about $600 \mathrm{~m}$ away from adjacent tomato fields and surrounded from South, West and East sides by vineyard orchards and from North side by area lacking (without) any vegetation. Tomato seeds ('Felat-eKimia' cultivar) were sown in the first half of April (2013) in rows distanced 1 meter. The farm was irrigated two or three times per week using tape irrigation system. Weeds were removed by hands twice in the whole growing season. Also, seedling were thinned manually and adjusted in rows with distance about $25-30 \mathrm{~cm}$ when they had 3-4 true leaves and maximum $7-8 \mathrm{~cm}$ height.

\section{Traps and their arrangement in the field}

Three of the most conventional solar LED light traps in Iran markets (Table 1), widely used for mass trapping of TLM and many of others moth pests (with and without the sex pheromone), along with water pan pheromone traps (control treatment) were arranged in a randomized complete design block with 7 treatments in three replicates. Each experimental plot was about $550 \mathrm{~m}^{2}$

The traps were: (1) Behroyan light trap; (2) Behroyan light trap baited sex pheromone; (3) Zist bani light trap; (4) Zist bani light trap baited sex pheromone; (5) Russell light trap; (6) Russell light trap baited sex pheromone and (7) water pan sex pheromone trap (control treatment). Behroyan and Zeist bani traps were manufactured in Iran but Russell light trap was imported from China. The important characters of the mentioned traps listed in Table 1.

All traps were charged automatically with sun light in day time and performed form sun set to 2 hours after mid night. Control treatment (water pan pheromone baited trap) had white water pan with 8 liter water capacity (Fig. 1) and baited with the same sex pheromone used in light traps. Although each trap had two pheromone baskets, only one sex pheromone of T. absoluta with $0.5 \mathrm{mg}$ dose (Sanidad Agricola, Econec, Ltd, Spain) was used in any one of traps baited sex pheromone (12 traps baited with pheromone) and renewed after 6 weeks. Some drops of hand washing liquid were added in water pans of all traps for killing captured insects and reducing water evaporation (Chermiti and Abbes, 2012). Traps were refilled with water twice per week due to hot weather and high respiration in the region. The traps were placed in the middle of each plot in the field once tomato seedlings had maximum $6-7 \mathrm{~cm}$ height. They were placed at ground level in the field at the beginning stage of the experiment and gradually increased their height according to the growth stage of the tomato plants and finally fixed above the plants canopy (Ferrara et al., 2001).

\section{Sampling methods}

The traps were checked once or twice per week and the number of T. absoluta and noctuid moths (Helicoverpa armigera, Spodoptera spp., Agrotis sp., etc.), Chrysopa carnea, C. septempunctata L. and Syrphid flies were counted.

Table 1. The relevant characters of light traps used for mass trapping of Tuta absoluta in the experiment

\begin{tabular}{ccccccc}
\hline Trap type & Number of lamps & pan color & Pan capacity $(\mathrm{Lr})$ & Solar pan size $(\mathrm{mm})$ & Producer \\
\hline Zist bani & 3 & blue & 10 & $40 \times 40$ & $110 \times 110$ & Behroyan Pars Co. Shiraz, Iran \\
Behroyan & 8 & red & 8 & $60 \times 60$ & Zist Paya Co. Tehran, Iran \\
Russell & 1 & white & 8 & China \\
\hline
\end{tabular}




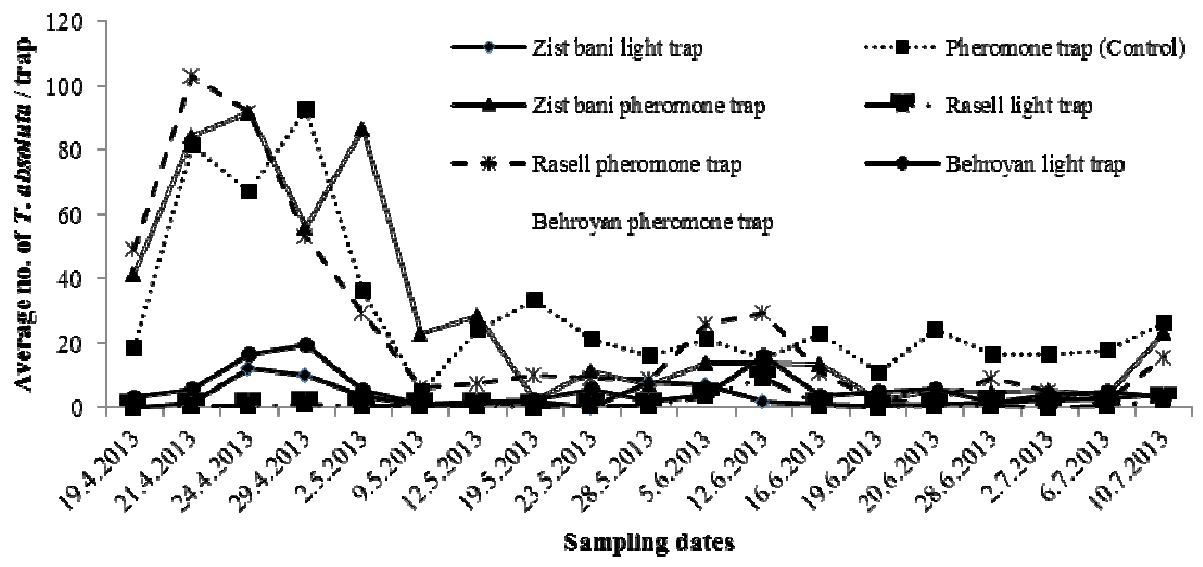

Fig. 1. Population fluctuations of T. absoluta in experimental tarps in various sampling dates

At harvesting time, 50 fruits were randomly collected from each plot and the number of infested and healthy fruit counted and the percentage of infested fruits in treatments was determined.

\section{Statistical analysis}

Data were evaluated through analysis of variance by using SAS software (version 9.1, SAS Institute, Cary, NC, USA) and mean comparisons of treatments were done with Duncan multiple tests $(\alpha \leq 0.01)$. The population dynamics of $T$. absoluta and noctuid moths in traps in various sampling dates were determinated.

\section{Results}

\section{Weekly capture of tomato leaf miner}

Mean weekly capture adults of tomato leaf miner (TLM) showed significant differences among treatments $\left(\mathrm{F}_{6,12}=58.51 ; \mathrm{P}<0.0001 ; \mathrm{CV} \%=17.78\right)$ at 0.01 percent probability level. The minimum weekly captured of TLM was observed in traps without sex pheromone, whereas the traps with sex pheromone had significantly higher captures of TLM than traps without sex pheromone (Table 2). All three light traps (without pheromone) were placed in the same statically group (c), while traps containing sex pheromone were placed in different statically groups. The maximum and minimum capture rate of TLM in traps containing sex pheromone were observed in Behroyan containing sex pheromone and Russell traps baited sex pheromone, respectively. There were no significant differences in average weekly capture of TLM between Behroyan traps containing sex pheromone $(54.71 \pm 1.18)$ and water pan pheromone traps ( $47.13 \pm 3.06$ adults). No significant differences were observed in average weekly capture of TLM in Zist bani traps containing sex pheromone ( $42.05 \pm 6.47$ adults) and Russell traps baited sex pheromone ( $39.02 \pm 2.28$ adults).

\section{Weekly capture of noctuid moths}

The average weekly captured noctuid moths showed significant differences among treatments $\left(\mathrm{F}_{6,12}=63.57\right.$; $\mathrm{P}<$ $0.0001 ; \mathrm{CV} \%=18.71)$ at 0.01 percent probability level. The maximum weekly captured noctuid moths were observed in Zist bani traps with sex pheromone (28.9 \pm 0.95). The minimum captured noctuid moths were observed in water pan pheromone traps $(0.73 \pm 0.27)$. There was no significant difference in the captured moths between water pan pheromone trap and Russell trap with pheromone $(2.76 \pm 0.57)$ and without pheromone $(1.49 \pm$ $0.27)$ (Table 2).

\section{Weekly capture of Chrysopa carnea}

Mean weekly capture of $C$. carnea in evaluated treatments were significant at 0.01 percent probability level $\left(\mathrm{F}_{6,12}=45.91 ; \mathrm{P}<0.0001 ; \mathrm{CV} \%=20.82\right)$.

Table 2. Mean weekly captured of $T$. absoluta adults and noctuid moths (mean $\pm \mathrm{SE}$ ) in experimental traps during whole growing season of tomato

\begin{tabular}{ccc}
\hline Traps & \multicolumn{2}{c}{ Mean (+SE) weekly capture } \\
\cline { 2 - 3 } & T. absoluta & Noctuid moths \\
\hline Behroyan light trap+ pheromone & $54.72 \pm 1.18 \mathrm{a}$ & $21.04 \pm 1.72 \mathrm{bc}$ \\
Behroyan light trap & $9.11 \pm 1.16 \mathrm{c}$ & $16.92 \pm 1.39 \mathrm{c}$ \\
Zist bani light trap+ pheromone & $42.05 \pm 6.47 \mathrm{~b}$ & $28.09 \pm 0.95 \mathrm{a}$ \\
Zist bani light trap & $4.94 \pm 0.24 \mathrm{c}$ & $25.39 \pm 0.57 \mathrm{ab}$ \\
Russell light trap+ pheromone & $39.28 \pm 2.28 \mathrm{~b}$ & $2.76 \pm 0.57 \mathrm{~d}$ \\
Russell light trap & $1.66 \pm 0.7 \mathrm{c}$ & $1,49 \pm 0.27 \mathrm{~d}$ \\
Water pan pheromone trap & $47.13 \pm 3.06 \mathrm{ab}$ & $0.73 \pm 0.27 \mathrm{~d}$ \\
\hline${ }^{*}$ Means with same letters in each column are not significant at 0.01 percent of probability level according DMRT.
\end{tabular}

${ }^{\circ}$ Means with same letters in each column are not significant at 0.01 percent of probability level according DMRT. 
478

The maximum weekly capture of the investigated predator was observed in Behroyan light trap without pheromone $(2.20 \pm 0.11)$, whereas the minimum weekly capture was observed in water pan pheromone trap $(0.06 \pm$ $0.06)$ and Russell traps and with $(0.33 \pm 0.06)$ and without sex pheromone $(0.20 \pm 0.11)$, respectively. Although capture rate of $C$. carnea in Zeist bani trap with pheromone $(1.33 \pm 0.06)$ were higher than within the same trap without pheromone $(1.02 \pm 0.11)$, there was no significant difference between both of them (Table 3 ).

\section{Weekly capture of syrphid flies}

Significant differences were observed in weekly capture of syrphid flies among treatments at 0.01 percent probability level $\left(\mathrm{F}_{6,12}=102.75 ; \mathrm{P}<0.0001 ; \mathrm{CV} \%=27.34\right)$. The maximum weekly capture of syrphid flies were observed in Zist bani light trap with pheromone (5.73 \pm $0.46)$ and without pheromone $(5.46 \pm 0.40)$, respectively while the other traps captured the minimum number of syrphid flies and all were placed in same statically group (b) (Table 3).

\section{Weekly capture of Coccinella septempunctata}

Significant differences were observed in capture rate of C. septempunctata among treatments at 0.01 percent probability level $\left(\mathrm{F}_{6,12}=43.34 ; \mathrm{P}<0.0001 ; \mathrm{CV} \%=18.84\right)$. The maximum and minimum weekly capture of this predator were observed in Zist bani trap without pheromone $(1.04 \pm 0.05)$ and water pan pheromone trap (zero capture), respectively. Capture rate of $C$. septempunctata in Behroyan traps with $(0.29 \pm 0.06)$ and without sex pheromone $(0.29 \pm 0.05)$ were not significant and both traps were placed in the same statically group (d). As well as, capture rate of $C$. septempunctata in Russell traps with pheromone $(0.5 \pm 0.02)$ and without pheromone $(0.44 \pm 0.04)$ were not significant and both traps were placed in the same statically group (c) (Table 3 ).

\section{Population fluctuations of tomato leaf miner}

The maximum population densities of $T$. absoluta were observed in the first of five sampling dates (in the other hand, ten days after trap placed in the field). Then, the population gradually decreased and was placed in the relatively constant level in the rest of the sampling dates (Fig. 2). The average capture rate of $T$. absoluta over growing the season in traps containing sex pheromone and light traps (without pheromone) were 10.6 and 1.09 adults/trap/night, respectively.

TLM density in the $1^{\text {st }}, 2^{\text {nd }}$ and $3^{\text {rd }}$ sampling dates in traps containing sex pheromone were 23.04, 44.04 and 43.83 adults/trap/night, respectively. Afterwards, capture rate rapidly decreased and from the $6^{\text {th }}$ sampling date (09.05.2013) onwards, the trend was placed in the relatively constant level (3.32 adults/trap/nightly) (Fig. 3). In total, capture rate of TLM in light traps was very low in comparison to traps baited sex pheromone. The maximum capture rate in light traps was observed in the in the $3^{\text {rd }}(4.83$ adults/trap/nightly) and the $4^{\text {th }}$ sampling dates (5.05 adults/trap/nightly), while capture rate in the other sampling dates were low (in average 0.57 adult /trap /night) (Fig. 3). Figs. 2 and 3 show the same TLM population pattern in the experimental field.

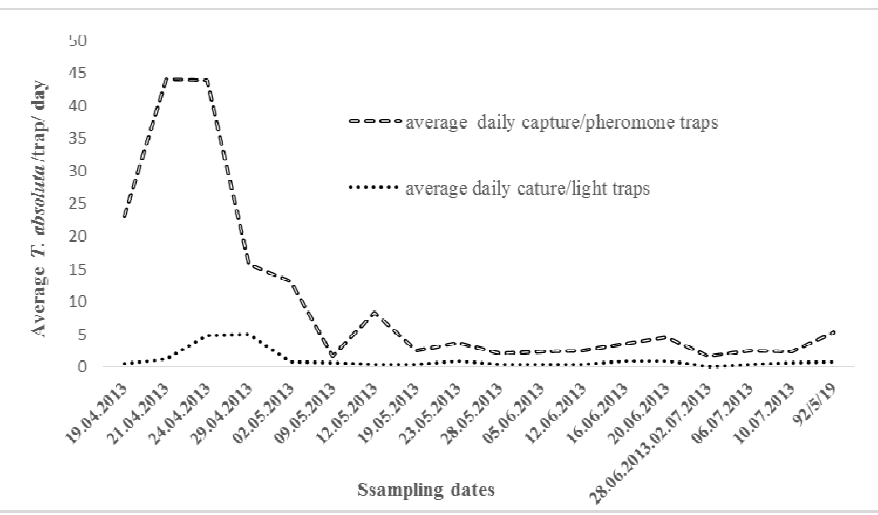

Fig. 2. Population fluctuations of $T$. absoluta adults in traps containing sex pheromone and traps lacking sex pheromone (light traps) in a tomato field

Table 3. Mean weekly captured of Chrysopa carnea, Coccinella septempunctata and Syrphid flies (Mean \pm SE) in experimental traps during whole growing season of tomato

\begin{tabular}{cccc}
\hline \multirow{2}{*}{ Traps } & \multicolumn{2}{c}{ Mean $(+$ SE) weekly capture rate of predators } \\
\cline { 2 - 4 } & Chrysopa carnea & Coccinella septempunctata & Syrphid flies \\
\hline Behroyan light trap+ pheromone & $1.6 \pm 0.2 \mathrm{~b}$ & $0.29 \pm 0.06 \mathrm{~d}$ & $0.2 \pm 0.11 \mathrm{~b}$ \\
Behroyan light trap & $2.2 \pm 011 \mathrm{a}$ & $0.29 \pm 0.05 \mathrm{~d}$ & $0.2 \pm 0.2 \mathrm{~b}$ \\
Zist bani light trap+ pheromone & $1.3 \pm 0.06 \mathrm{bc}$ & $0.75 \pm 0.08 \mathrm{~b}$ & $5.7 \pm 0.46 \mathrm{a}$ \\
Zist bani light trap & $1.2 \pm 0.11 \mathrm{c}$ & $1.04 \pm 0.05 \mathrm{a}$ & $5.46 \pm 0.40 \mathrm{a}$ \\
Russell light trap+ pheromone & $0.33 \pm 0.06 \mathrm{~d}$ & $0.05 \pm 0.02 \mathrm{~cd}$ & $013 \pm 0.6 \mathrm{~b}$ \\
Russell light trap & $0.2 \pm 0.11 \mathrm{~d}$ & $0.44 \pm 0.04 \mathrm{c}$ & $0.000 \mathrm{~b}$ \\
Water pan pheromone trap & $0.06 \pm 0.06 \mathrm{~d}$ & $0.000 \mathrm{e}$ & $0.000 \mathrm{~b}$
\end{tabular}




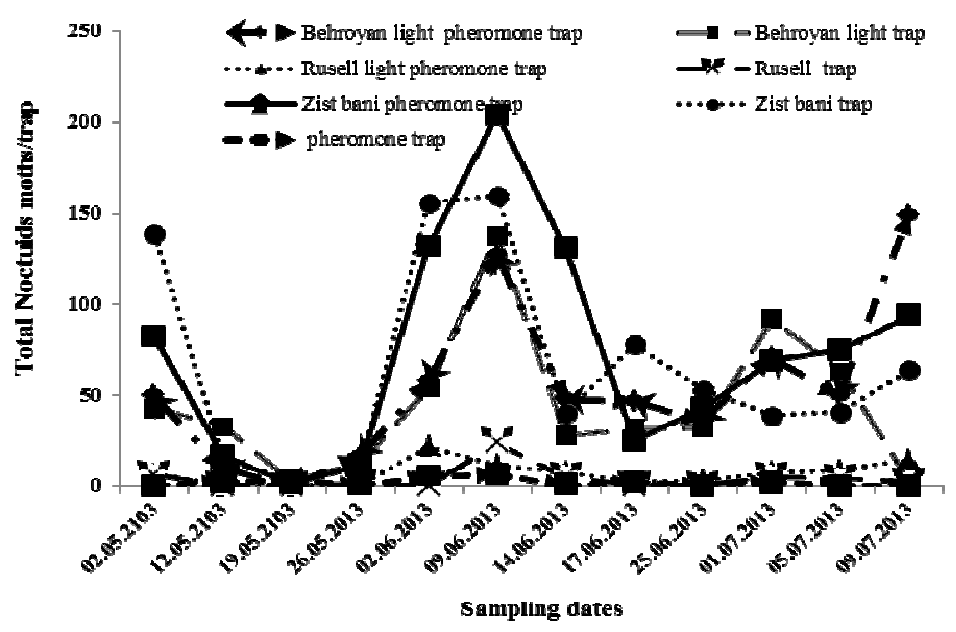

Fig. 3. Population fluctuations of noctuid moths in various traps in different sampling dates

\section{Population fluctuations of noctuid moths}

As shown in Fig. 3, the population peak of noctuid moths in various sampling dates was observed between 2013.05.26 and 2013.06.17 and all traps had the same pattern in this period. The most important captured moths were Spodoptera spp., Agrotis spp. and Helicoverpa armigera. In the most sampling dates, Zist bani traps with and without sex pheromone captured the maximums number of the moths, followed by Behroyan with and without pheromone traps. The capture rates of the moths by Russell trap with and without pheromone were low.

\section{Discussion}

Results showed that the performance of traps baited sex pheromone were 9 times $(45.73 \pm 6.86$ moths/trap/week) higher than traps lacking pheromone $(5.23 \pm 3.78$ moths/trap/week). In the other hand, $92 \%$ of the 7,152 adults of all captured TLM were (21 traps) captured by traps containing sex pheromone ( 9 light - pheromone traps +3 water pan traps) and $8 \%$ by traps lacking sex pheromone (9 light traps).

There are many factors affecting the efficiency of trapping system. Some factors are under the control of researchers and can be manipulated by them, including trap design (size, color and shape), attractant characteristics (source, composition, life span, dose and replacement time), trap position (height, position with respect to vegetation and trap density), pest and natural enemies and their population densities (Uchôa-Fernandes et al., 1994; Howse, 1998; Ferrara et al., 2001, Salas, 2004; Silva, 2008; Bolckmans, 2009; Abbes et al., 2011, Chermiti and Abbes, 2012; Caparros Megido et al., 2013), whereas other factors such as moon light and weather condition (temperature, relative humidity, wind, rain) are not generally under the control of researchers and cannot be manipulated directly (McGeachie, 1989; Yela and Holyoak, 1997; Holloway et al., 2001). Besides the above mentioned factors, parthenogenesis in adult females (Caparros Megido et al., 2013) and polygenic in adult males (Silva, 2008) are others important factors affecting the mass trapping performances of T. absoluta.
In the present experiment, not only the attractant type (light, pheromone or combination of light and pheromone) had the main role on traps efficiency, but also using some of the recommended key points in literatures for maximizing traps' efficiency, useful in taking successful results. For instance, (1) an isolated tomato field was selected as experimental place because the isolation of the tomato fields reduces the rate of adults immigration particularly the fertilized females from adjacent fields within the experimental fields and increase the efficiency of mass trapping system (Harbi et al., 2012; Caparros Megido et al., 2013). (2) All traps were placed at ground levels in the early growth stage of tomato plants (seedlings had maximum 10 centimeter height and 3-4 leaves) and gradually trap height was adjusted according to the growth stage of the tomato plants. Literatures showed that mass trapping experiments were often successful in areas with low to medium pest population (Silva, 2008; Vacas et al., 2011; Cocco et al., 2012). For successful mass trapping programs, traps must be deployed early in the plant growth cycle, when T. absoluta populations are present at low densities (El-Sayed et al., 2006). Also, the height of the trap in the crop influences males capture and is related to the height of the tomato plants (Uchôa-Fernandes et al., 1994; Ferrara et al., 2001). (3) Water pan traps were used in the experiment because they are easier to maintain and have a larger trapping capacity than Delta traps and also these traps are the most common pheromone traps used for mass trapping of $T$. absoluta (El-Sayed et al., 2006). Of course, water pan traps needed frequent water refilling under hot weather conditions in the summer ((Emre and Orkun, 2016). (4) Pheromone capsule dispenser with standard dose $(0.5 \mathrm{mg})$ was used to increase the attraction rate of the adult males. This dose were recommended as the standard dose in mass trap pining experiments of T. absoluta (El-Sayed et al., 2006) in areas with low to medium pest population. (5) Sex pheromone dispenser in traps was replaced after 6 weeks as recommended by the manufactured company and the water solution inside the water pan traps were renewed before traps became saturated with the attracted insects. (6) All traps (21 traps) were uniformly distributed in the field with $23.5 \mathrm{~m}$ apart. Recent studies on the range of attraction of 
480

pheromone traps to some Agrotis species suggested that an estimated distance of $20 \mathrm{~m}$ between individual traps would be needed to permit substantial mass trapping (Sufyan et al., 2011).

There are many reasons for higher performance of traps containing sex pheromone than light traps: for instance, (1) sex pheromone are species-specific chemicals that are active in extremely low doses and play an important role in integrated pest management for structural, landscape, agricultural or forest pest (Riedl et al., 1976; Jones, 1998) while light is a visual attractant which attracts many insect species. In Europe, Cydia pomonella, Eupoecilia ambiguella and Lobesia botrana were successfully controlled using pheromone-based management techniques (Ridgway et al., 1990; Witzgall and Arn, 1997). (2) Attraction radius of sex pheromone is often more than light; therefore, traps containing sex pheromone are able to attract more insects from farther areas. Attraction radios were smaller than 30 meters in the most situations for 'normal' light sources in entomological research (Butler and Kondo, 1991; Muirhead-Thompson, 1991). (3) The performance of light traps is highly affected by unmanageable factors such as temperature, rainfall, wind speed, moonlight and cloud cover (Holyoak et al., 1997; Yela and Holyoak, 1997), but these factors have lower effects on sex pheromone traps. Generally, warm, moist and moonless nights produce highest specimen counts in light traps and conversely, the number of individuals caught in the light trap decreased as fullness of the moon increased, as well as, strong winds reduced light trap catches (Wallace, 1869).

Light traps have been widely used to control agricultural pests in developing countries such as China (Ma et al., 2009), India (Srivastava et al., 1992) and Brazil (Oliveira et al., 2008). In China, currently commercial light traps are being used by the Chinese Ministry of Agriculture to control agricultural pests over an area of more than 32 million ha in 30 provinces. Although there were no significant differences in the capture rate of $T$. absoluta in light traps lacking sex pheromone, capture rate in Behroyan light trap without sex pheromone was nearly twice than Zist bani and Russell traps without pheromone (Table 2). The higher performance of Behroyan trap with and without sex pheromone than Zist bani and Russell traps with and without sex pheromone, could be related to the factors like color of water pan trap, volume of water pan, wave length and the number of light lamps in traps. Color of water pan in Behroyan was red, but in Zist bani and Russell traps were blue and white, respectively. Investigation showed traps containing dark color (black, red, green and blue) attracted higher number of TLM males than lighter color traps (yellow and white). Also, the mean catch of $T$. absoluta moths per trap in an experiment in Egypt were estimated $35.88,17.58,12.33$ and 10.71 for red, blue, green and yellow trap, respectively (Taha et al., 2012). Therefore, the current results are in agreement with the previous data.

Trap shape and size had important effects on traps catch size. The capacity of water pan in Behroyan trap were 10 liter, whereas in Zist bani and Russell water pan were about 8 liter, therefore, larger trapping capacity in Behroyan trap than Zist bani and Russell traps could be the another factor resulted in higher capture rate of this trap. The effective wavelengths and intensities vary among species (Yang et al., 2003). Wave length in Behroyan trap was reported as 400 $\mathrm{nm}$ by the manufactured company, but there was no information about wave length of Zist bani and Russell type light traps. Insects are sensitive to a broad spectrum of light ranging from ultraviolet (UV) to red (Stark and Tan, 1982). However, not all species are attracted to light to the same extent (Bowden, 1982; Butler et al., 1999), but Lepidoptera are strongly attracted to UV and blue color, with a peak atraction in about $400 \mathrm{~nm}$ wavelenghts (Cowan and Gries, 2009). Behroyan trap had 8 LED lamps, whereas Zist bani and Russell trap had one lamp in each trap. A number of light lamps had positive effects on attraction rate of insects because increased intensity of light is more effective than low-intensity light in attracting moths (Stremer, 1959).

As shown in Fig. 2, in the first ten days after traps installation in the field, TLM population in traps containing sex pheromone were higher (162.82 adult/traps/week) than action threshold (using insecticides) mentioned in some previous studies (Benvenga et al., 2007; Stole et al., 2009), but high performance of traps, specially traps baited sex pheromone, resulted in high reduction of TLM population (18.5 adult/ traps /week) and lowering the pest population under the action threshold in the rest period of tomato growing seasons (about 2 months).

Based on the number of adult's males of $T$. absoluta caught in pheromone traps, the risk of infestation will be low for 1 to 3 captured moth per week, moderate for 4 to 30 captured moth per week and high for more than 30 moths per week (Stol et al., 2009). However, mass trapping would likely be more effective when integrated with recommended insecticide, fortunately no insecticide was used in this study and fruits infestation rate at harvesting time were less than 5 percent. Using insecticides for management of T. absoluta is largely based on adult captures in sexual pheromone traps (Benvenga et al., 2007), as adult catches are correlated with larval damages and yield losses (Faccioli, 1993). In Brazil, economic threshold were determined as $45 \pm 19.50 \mathrm{~T}$. absoluta daily cached adults using pheromone traps (Benvenga et al., 2007), while in Chile, economic threshold were reported as 100 males per pheromone trap per day. The hereby results revealed that mass traping with traps baited sex pheromone could be an effective tools for mass traping of TLM. The results confirmed those of Emre and Orkan (2016) in Turkey. Mass trapping experiments of TLM have been successful in tomato fields with low pest population, isolated tomato fields and controlled spaces such as greenhouses (Filho et al., 2000; Vacas et al., 2011; Cocco et al., 2012, 2013).

In greenhouse condition, using at least one trap per 500 square meters, moth populations was significantly reduced as part of an integrated pest management program (Stoltman et al., 2010). In conclusion, traps baited with sex pheromones are absolutely necessary for effective mass trapping of $T$. absoluta in open tomato fields in Fars climatic condition. Also, timely placing of traps in the field, selection of isolated tomato fields, using water pan traps, using standard pheromone dispensers (at least $0.5 \mathrm{mg}$ dose) and replacing of pheromone dispensers after two months will increase trap efficiency in mass traping programs of TLM. 
As shown in Table 1, light traps captured a large number of the above mentioned moths because they are the most species-rich family in the Lepidoptera (Scoble, 1992) and usually comprise a larger proportion of captures in light and bait traps than any other family (White, 1991; Cowan and Gries, 2009). The maximum and minimum number of noctuid moths was captured by Zist bani and Russell traps respectively. Helicoverpa armigera Hübner, Spodoptera sp, Agrotis spp. were the main species captured by all light traps. They are the most important pests of tomato in Iran; among them, Helicoverpa armigera is the fruit borer with high potential of damaging, specially in the first generation (Khanjani, 2013). It is known that moth catches are significantly influenced by the type of trap, sampling mode, time of day, season and duration of sampling (Thomas and Thomas, 1994) and light sources employed and its spectral composition (Fayle et al., 2007). In addition, a range of a biotic factors affect the efficiency of light traps, such as temperature, rainfall, moonlight and cloud cover (Holyoak et al., 1997; Yela and Holyoake, 1997). In the present experiment, differences in noctuid moths captured in traps were related to factors like color of pans, number of lamps and traps wavelength. Trap color has been reported to be a significant factor affecting catches of several moth species (Childers et al., 1979; Mitchell et al., 1989). Color of water pan in Zist bani was blue, while in Behroyan and Russell were red and white, respectively. Also, the number of LED lamps in Zist bani was 3, whereas in Behroyan was 8 and Russell was 1. Yela and Holyoake (1997) claim that the most important factor affecting catch size in light traps is the light intensity, with more moths being caught at higher intensitie. In contrast, Williams (1951) found that a $125 \mathrm{~W}$ ultraviolet bulb caught greater numbers of moths than a 200W standard bulb. Generally, each species has sets of wavelengths to which it is most attracted or repelled (Fayle et al., 2007). The wavelength in Behroyan was reported 400 $\mathrm{nm}$, while in Zist bani and Russell trap were unknown. Ting et al. (1974) have reported that in the range of visible light, $H$. armigera (Hübner) and $H$. assault_Guenée exhibited strong attractiveness to the light of $405 \mathrm{~nm}$.

Literatures showed a large numbers of non-target species especially beneficial insects are attracted and killed by light traps (Nabli et al., 1999; 2009), so that evaluating the potentially negative impacts of experimental light traps on the major predators existing in tomato fields were important for this study. Although significant differences were observed in the number of attracted predators $(C$. carnea, C. septempunctata and syrphid flies) among traps, the total numbers of attracted predators in three used light traps (with and without pheromone) were low. Therefore, all three light traps used in the experiment could be used as beneficial friendly tools for mass trapping of TLM. Li et al. (2015) showed various light traps including yellow light trap, black light trap, New Jersey light trap, UV light trap and CDC light trap attracted a low number of Chrysopa sp.

Nowadays, we can reduce the attraction rate of nontarget insects, especially beneficial insects, by using artificial light traps containing special wavelength and color (Antignus, 2000; Duehl et al., 2012). LED solar light traps used in the current experiment were new types of light traps with selective wavelengths. Besides wavelength, trap color can also influence the attractiveness of light traps for natural enemies (Blackmer $e t$ al., 2008). In the hereby experiment, the maximum numbers of syrphid flies were attracted by Zist bani traps containing blue water pans, while the highest numbers of Chrysopa sp. were attracted by Behroyan light traps containing red water pans. The obtained results confirmed those of Rodriguez-Saona et al. (2012) in New Jersey (USA) and Hoback et al. (1999) in Maricopa in Arizona (USA). The maximum numbers of $C$. septempunctata were attracted by Zzist bani and Behroyan light traps, while the minimum number was observed in Russell traps with white water pans, whereas the total cached number of C. septempunctata by all three light traps were less than 200 ladybirds. On the basis of comparison of attraction rate to different wave lengths of light, ladybirds were most attracted to backlight traps (Nabile et al., 1999). In conclusion, some types of water pan light traps baited sex pheromone showed good potential for mass trapping and suppressing the populations of $T$. absoluta in the experimental fields.

\section{Conclusions}

For successful mass trapping of tomato leaf miner, the following key factors should be considered: 1) Proper placement of traps in the early growth stage of tomato plants (immediately after seed germination, in direct seed planting or after transplanting); 2) using isolated field for mass trapping; 3) proper trap density (at least one trap per $\left.500 \mathrm{~m}^{2}\right)$; 4) using pheromone dispensers with proper dose (at least $0.5 \mathrm{mg}$ dose) and 5) increasing trap height according to plant growth. The results show that Behroyan and Zist-bani light traps baited sex pheromones can be used as an effective and eco-friendly tool for mass trapping of $T$. absolute.

\section{References}

Abbes K, Harbi A, Chermiti V (2012). Comparative study of 2 protection strategies against Tuta absoluta (Meyrick) in late open field tomato crops in Tunisia. EPPO Bulletin 42(2):297-304.

Abdul Razzak AS, Al Yasiri II, Fadhil HQ (2010). First record of tomato borer (tomato moth) Tuta absoluta (Meyrick) (Lepidoptera: Gelechiidae) on tomato crop in Iraq. Arab and Near East Plant Protection Newsletter 51:34.

Anonymous (2014). Statics of agricultural productions. Vol 1, Field Crops Productions, Statics Division, Economic and Planning Deputy, Ministry of Agriculture, Iran pp 158.

Antignus Y (2000). Manipulation of wavelength dependent behavior of insects: an IPM tool to impede insects and restrict epidemics of insect borne viruses. Virus Research 71(1-2):213-220.

Baniameri V, Cheraghian A (2012). The current status of Tuta absoluta in Iran and initial control strategies. In: $\mathrm{EPPO} / \mathrm{IOBC} / \mathrm{FAO} / \mathrm{NEPPO}$ Joint International Symposium on management of Tuta absoluta (tmato borer), 16-18 November, Agadir, Morocco.

Benvenga SR, Fernandes OA, Gravena S (2007). Decision making for integrated pest management of the South American tomato pinworm 
482

based on sexual pheromone traps. Horticultura Brasileira 25(2):164 169.

Blackmer JL, Byers JA, Rodriguez-Saona C (2008). Evaluation of color traps for monitoring Lygus spp, design, placement, height, time of day, and non-target effects. Crop Protection 27(2):171-181.

Bolkmans K (2009). Integrated pest management of the exotic invasive pest Tuta absoluta. $4^{\text {th }}$ Annual Bio-control Industry Meeting, International Bio-control Manufacturers Association, Lucerne, Switzerland, management. Chapman and Hall, London pp 299.

Bowden J (1982). An analysis of factors affecting catches of insects in lighttraps. Bulletin of Entomological Research 72(4):535-556.

Butler L, Kondo V (1991). Macrolepidopterous moths collected by backlight trap at Cooper's Rock State Forest, West Virginia: a baseline study. Agriculture and Forestry Experiment Station, West Virginia University, Bulletin 705:1-25.

Cabello T, Gallego JR, Vila E, Soler A, Pino M, Carnero A, HernándezSuárez E, Polaszek A (2009). Biological control of the South American tomato pinworm, Tuta absoluta (Lep: Gelechiidae), with releases of Trichogramma achaeae (Hym: Trichogrammatidae) in tomato greenhouses of Spain. IOBC/WPRSBulletin 49:225-230.

Caparros Megido R, Haubruge E, Verheggen F (2013). Pheromone-based management strategies to control the tomato leaf miner, Tuta absoluta (Lepidoptera: Gelechiidae): a review. Biotechnologie, Agronomie, Societe and Environment 17(3):475-482.

Cardé RT (2007). Using pheromones to disrupt mating of moth pests. In Kogan M, Jepson P (Eds). Perspectives in ecological theory and integrated pest management. Cambridge, UK. Cambridge University Press pp 122-169.

Chermiti B, Abbes K (2012). Comparison of pheromone lures used in mass trapping to control the tomato leaf miner Tuta absoluta (Meyrick, 1917) in industrial tomato crops in Kairouan (Tunisia).EPPO Bulletin 42(2):241-248.

Childers SH, Holloway RL, Pollet DK (1979). Influence of pheromone traps color in capturing lesser Peachtree borer and Peachtree borer males. Journal ofEconomic Entomology72(4):506-508.

Cocco A, Deliperi S, Delrio G (2012). Potential of mass trapping for Tuta absoluta management in greenhouse tomato crops using light and pheromone traps. IOBC/WPRSBull 80:319-324.

Cocco A, Deliperi S, Delrio G (2013). Control of Tuta absoluta (Meyrick) (Lep., Gelechiidae) in greenhouse tomato crops using the mating disruption technique. Journal of AppliedEntomology 137(1-2):16-28.

Cowan T, Gries G (2009). Ultraviolet and violet light: attractive orientation cues for the Indian meal moth, Plodia interpunctella. Entomologia Experimentalis et Applicata 131(2):148-158.

Desneux N, Eric W, Kris AGW, Giovanni B, Salvatore A, et al., Alberto U (2010). Biological invasion of European tomato crops by Tuta absoluta: ecology, geographic expansion and prospects for biological control. Journal of Pest Science 83(3):197-215.

Desneux N, Luna MG, Guillemaud T, Urbaneja A (2011). The invasive South American tomato pinworm, Tuta absoluta, continues to spread in Afro-Eurasia and beyond: the new threat to tomato world production. Journal of PestScience 84(4):403-408.
Duehl AJ, Arbogast RT, Sheridan AB, Teal PE (2012). The influence of light on small hive beetle (Aethinatumida) behavior and trap capture. Apidologie 43(4):417-424.

El-Sayed AM, Suckling DM, Wearing CH, Byers JA (2006). Potential of mass trapping for long-term pest management and eradication of invasive species. Journal of Economic Entomology 99(5):1550-1564.

Emre A, Orkun BK (2016). Mass trapping low-density populations of Tuta absoluta with various types of traps in field-grown tomatoes. Journal of Plant Diseases and Protection 123(2):51-57.

Faccioli G (1993). Relationship between males caught with low pheromone doses and larval infestation of Argyrotaenia pulchellana. Entomologia Experimentalis et Applicata 68(2):165-170.

Fayle TM, Sharp RE, Majerus MEN (2007). The effect of moth traps type on catch size and composition in British Lepidoptera. British Journal of Entomology and Natural History20(4):221-232.

Ferrara FAA, Vilela N, Jham E, Eiras M, Picanco B, Attygale A Meinwald J (2001). Evaluation of the synthetic major component of the sex pheromone of Tuta absoluta (Meyrick) (Lepidoptera: Gelechiidae). Journal ofChemical Ecology 27(5):907-917.

Filho MM, Vilela EF, Jham NG, Attygalle A, Svatos A Meinwald J (2000). Initial studies of mating disruption of the tomato moth, Tuta absoluta (Lepidoptera: Gelechiidae) using synthetic sex pheromone. Journal of the Brazilian Chemical Society 11(6):621-628.

Galarza J (1984). Evaluacion en laboratorio de algunas plantas Solanaceas. Posibles Hospederas de la Polilla del Tomate Scrobipalpula absoluta. IDIA $421-424$

Gonzalez-Cabrera J, Molla O, Monton H, Urbaneja A (2011). Efficacy of Bacillus thuringiensis (Berliner) for controlling the tomato borer, Tuta absoluta (Meyrick) (Lepidoptera: Gelechiidae). BioControl 56(1):7180.

Harbi A, Abbes K, Chermiti B (2012). Evaluation of two methods for the protection of tomato crops against the tomato leaf miner Tuta absoluta (Meyrick) under greenhouses in Tunisia. EPPO Bulletin 42(2):317321.

Hassan N, Al-Zaidi S (2010). Tuta absoluta - pheromone mediated management strategy. International Pest Control 52(3):158-160.

Hoback W, Svatos T, Sponer S, Higley G (1999). Trap color and placement affect estimates of insect family-level abundance and diversity in a Nebraska salt marsh. Entomologia Experimentalis et Applicata 91(3):393-402.

Holyoak M, Jarosik V, Novak I (1997). Weather-induced changes in moth activity bias measurement of long-term population dynamics form light trap samples. Entomologia Experimentais et Applicata 83(3):329-335.

Howse P (1998). Pheromones and behavior. In: Howse P, Stevens I, Jones $\mathrm{O}$ (Eds). Insect pheromones and their use in pest management. London, UK: Chapman \& Hall pp1-130.

Intachat J,HollowayJD, Staines H (2001).Effects of weather and phenology on the abundance and diversity of geometrids moths in a natural Malaysian rain forest. Journal of Tropical Ecology 17(3):411-429.

Jones O (1998). Practical applications of pheromones and other semiochemicals. In: Howse P, Stevens I, Jones O (Eds). Insect pheromones and their use in pest management. London, UK: Chapman \& Hall pp 263-355. 
Khanjani M (2013). Vegetables pests in Iran. MSc Thesis Aboali - sina University, Iran.

Kilic T (2010). First record of Tuta absoluta in Turkey. Phytoparasitica 38(3):243-244.

Korycinska A, Moran H (2009). South American tomato moth (Tuta absoluta): plant pest fact sheet. Sand Hutton, York, UK, FERA.

LiC, Smith ML, Fulcher A, Kaufman, PE,Zhao TV, Xue ZD (2015). Field evaluation of three new mosquito light traps against two standard light traps to collect mosquitoes (Diptera: Culicidae) and non-target insects in Northeast Florida. Florida Entomologist 98(1):114117.

Ma CS, Ma G, Chang XQ, Yang HP (2009). Environment friendly methods for controlling cotton bollworm moths, Helicoverpa armigera. China Journal of Environment and Entomology31:220-226.

McGeachie WJ (1989). The effects of moonlight iluminance, temperature and wind speed on light-trap catches of moths. Bulletin of Entomological Research 79(2):185-192.

Meyrick E (1917). Descriptions of South American micro-Lepidoptera. transactions of the Royal Entomological Society ofLondon 65(1):1-52.

Mitchell ER, Agee HR, Heath RR (1989). Influence of pheromone traps color design on capture of male velvet bean caterpillar and fall armyworm moths Lepidoptera: Noctuidae). Journal of Chemical Ecology 15(6):1775-1784.

Muirhead-Thomson RC (1991). Trap responses of flying insects: the influence of trap design on capture efficiency. Academic Press, London.

Nabile H, Baiely WC (1999). Beneficial insect attraction to light traps with different wavelengths. Biological Control 16(2):185-188

Oliveira C, Veloso VR, Barros RG, Fernandes PM, Souza ER (2008). Capture of Tuta absoluta (Meyrick) (Lepidoptera:Gelechiidae) with light trap in tomato crop. Pesquisa Agropecuaria Tropical 38:153-157..

PereiraJMM,Zanuncio TV,ZanuncioJC, Pratissoli D (2001). Lepidoptera pests collected in Eucalyptus urophylla plantations during five years in Três Marias, State of Minas Gerais, Brazil. Revista de Biologia Tropical 49(3-4):997-1006.

Pereyra PC, Sanchez NE (2006). Effect of two Solanaceous plants on developmental and population parameters of the tomato leaf miner, Tuta absoluta (Meyrick) (Lepidoptera: Gelechiidae). Neotropical Entomology 35(5):671-676.

Ridgway RL, Silverstein RM, Inscoe MN (1990). Behavior-modifying chemicals for insect management: applications of pheromones and other attractants. Marcel Dekker, New York.

Ridgway RL, Inscoe MN, Dickerson WA (1990). Role of the boll weevil pheromone in pest management. In: Ridgway RL, Silverstein RM, Inscoe $\mathrm{MN}$ (Eds). Behavior-modifying chemicals for insect management pp $437-471$.

Riedl HC, Roft B, Howitt AJ (1976). Forecasting codling moth phenology based on pheromone trap catches and physiological-time models. The Canadian Entomologist 108(5):449-460.

Rodriguez-Saona CR, Byers JA, Schiffhauer D (2012). Effect of trap color and height on captures of blunt-nosed and sharp-nosed leafhoppers (Hemiptera: Cicadellidae) and non-target arthropods in cranberry bogs. Crop Protection 40:132-144.

Rodriguez-Saona CR, Stelinski LL (2009). Behavior-modifying strategies in IPM: theory and practice. Integrated pest management: innovationdevelopment process. Springer, Dordrecht pp 263-315.
Salas J (2004). Capture of Tuta absoluta (Lepidoptera: Gelechiidae) in traps baited with its sex pheromone. Revista Colombiana de Entomologia 30(1):75-78.

Salazar ER, ArayaJE (2001). Respuesta de la polilla del tomate, Tuta absoluta (Meyrick), ainsecticidas en Arica. Agricultura Técnica 61(4):429-435.

Scoble MJ (1992). The Lepidoptera. Form function and diversity. Oxford University Press, Oxford.

Silva SS (2008). Fatores da biologia reprodutiva que influenciam o manejo comportamental de Tuta absoluta (Meyrick) (Lepidoptera: Gelechiidae). MS cThesis Universidade Federal Rural de Pernambuco (Brasil).

Srivastava CP, Pimbert M (1992). Monitoring of Helicoverpa (= Heliothis) Armigera (Hubner) moths with light and pheromone traps in India. International Journal of Tropical Insect Science 13 (2):205-210.

Stark WS, Tan K (1982). Ultraviolet light: photosensitivity and other effects on the visual system. Photochemistry and Photobiology 36(3):371-380.

Stol W, Griepink FC, Van Deventer F (2009). Tuta absoluta: a new pest for tomato production in Europe. Phytoma Espana.

Stremer RA (1959). Spectral response of certain stored-product insects to electromagnetic radiation. Journal of Economic Entomology 52(5):888-892.

Sufyan M, Neuhoff D, Furlan L (2011). Assessment of the range of attraction of pheromone traps to Agriotes lineatus and Agriotes obscurus. Agricultural and Forest Entomology 13(3):313-319.

Taha AM, Homam BH, Afsah AFE, Fatma D (2012). Effect of trap color on captures of Tuta absoluta moths (Lepidoptera: Gelechiidae). International Journal of Environmental Science and Technology 3:4348.

Thomas AW, Thomas GM (1994). Sampling strategies for estimating moth species diversity using a light trap in a north eastern softwood forest.Journal of Lepidopterists' Society 48:85-105.

Ting YC, Kao WT, Li MD (1974). Study on the photo- tactic behavior of nocturnal moths: the response of Heliothis armigera (Hübner) and Heliothis assulta Guenée to different monochromatic light. Acta Entomologia Sinica 17(3):307-316.

Torres JB, Evangelista W, Barras R, Guedes NC (2002). Dispersal of Podisus nigrispinus (Het. Pentatomidae) nymphs preying on tomato leaf miner: effect of predator release time, density and satiation level. Journal of AppliedEntomology 126(6):326-332.

Torres JB, Faria CA, Evangelista WS, Pratissoli D (2001). Within plant distribution of leaf miner Tuta absoluta (Meyrick) immatures in processing tomatoes, with notes on plant phenology. International Journal of Pest Management 47(3):173-178.

Uchoa-Fernandes MA, Della-Lucia TMC,Vilela EF (1995). Mating, oviposition and pupation of Scrobipalpuloides absoluta(Meyr.) (Lepidoptera: Gelechiidae). Anais da Sociedade Entomologica do Brasil 24(1):159-164.

Uchôa-Fernandes MA,Vilela EF (1994). Field trapping of the tomato worm Scrobipalpula absoluta (Meyrick) (Lep, Gelechiidae). Anais da Sociedade Entomologica do Brasil 23(2):271-277.

Urbaneja A, Vercher R, Navarro V, Garcia-Mari F, Porcuna JL (2007). La pollila del tomate, Tuta absoluta. Phytoma-Espana: La Revista Profesional deSanidad Vegetal 194:16-23. 
484

USDA APHIS (2011). New pest response guidelines: tomato leaf miner (Tuta absoluta). Washington, DC: United States Department of Agriculture.

Vacas S, Alfaro C, Primo J, Navarro-Llopis V (2011). Studies on the development of a mating disruption system to control the tomato leaf miner, Tuta absoluta Povolny (Lepidoptera: Gelechiidae). Pest Management Science 67(11):1473-1480.

Vargas H (1970). Observaciones sobre la biologia enemigos naturales de las polilla del tomate, Gnorimoschema absoluta (Meyrick). Depto Agricultura, Universidaddel Norte-Africa 1:75-110.

Viggiani G, Filella F, Ramassini W, Foxi C (2009). Tuta absoluta, nuovo lepidottero segnalato anche in Italia. Informatore Agrario 65(2):66-68.

Wallace AR (1869). The Malay Archipelago: the land of the orangutan and the bird of paradise: a narrative of travel, with studies of man and nature. Macmillan, London.
White EG (1988). Sampling frequency and the analysis of light-trapping data. New ZeelandEntomologist 11(1):81-84.

Witzgall P, Arn H (1997). Technology transfer in mating disruption. IOBC/WPRSBulletin 20(1).

Yang EC, Lee DW, Wu WY (2003). Action spectra of photo tactic responses of the flea beetle, Phyllotreta striolata. Physiological Entomology 28(4):362-368.

Yela J, Holyoak M (1997). Effects of moonlight and meteorological factors on light and bait trap catches of noctuid moths (Lepidoptera: Noctuidae). Environmental Entomology 26(6):1283-1290. 